\title{
FORECASTING THE STRENGTH OF REINFORCED POLYMER COMPOSITE USING STATISTICAL ANALYSIS METHOD
}

\author{
R. Chatys", M. Kleinhofs**, A. Panich ${ }^{* * *}$, K. Piernik ${ }^{\dagger}$
}

\begin{abstract}
The article discusses and attempts to analyze the composite structural interrelations and anisotropic properties, using the proposed methodology for processing the population of strength data (S) and the Young's modulus (E) for the "elementary bundle of components" and the resulting composite fiber material, using the vacuum bag method. It was shown, that the methodology, based on the method of calculation (the Kolmogorov test) and the graphical method, confirms the validity of the accepted distribution for the population data set $S$. The modified data E, using the following methodology, as a result of not only the complexity of the structure, but also the technological parameters of the composite formation, can confirm, or not, the correctness of the accepted distribution.
\end{abstract}

Keywords: composite, mechanical properties, modeling, methodology of statistical processing

\section{Introduction}

Composites composed of reinforcing fibers and polymer matrix are increasingly used in the construction of machines, transport equipment, construction, arms industry and others. These materials are currently decisive in the design of strength properties in many controlled (Chatys et al., 2010) and flying (Urbahs et al., 2013) objects.

Due to specific features, such as: ease of forming, high impact strength, durability and elasticity, and the ability to easily adapt composite properties to a specific purpose, there is an increasing demand for computational models taking into account the methodology of data processing (Blasiak, 2017).

\section{Model strength parameters of the polymer composite}

Mechanics of composites with a polymer matrix is based on the theory of deformation and destruction. When we create a calculation model (scheme), we aim to link the characteristics of the composite components to the strength of the finished composite formation and the final product. The mathematical model of polymer composite strength (including physical characteristics), can be expressed as:

$$
S_{l}=F\left[(\Psi, d, k, A)_{f, v}, \Psi_{m}\left(E, m, \mu, G, S, \varepsilon_{p}\right)_{f / m}, S_{b}, S_{R}, S_{a}\right]
$$

where: S, $\varepsilon$ - stress and deformation; $\Psi, \mathrm{d}, \mathrm{k}, \mathrm{A}$ - volume, size, amount and distribution of fibers; $\mathrm{L}, \mathrm{f}$, $\mathrm{f}_{\mathrm{m}}, \mathrm{v}, \mathrm{m}$ - indexes relating to the layers, microplastics, matrix fibers; $\mathrm{E}, \mu, \mathrm{G}$ - Young's modulus, Poisson coefficient, Kirchhoff module; P, b, R, a - indexes, referring to boundary destruction at the surface border layer, critical and applied stress.

\footnotetext{
Research Assistant Rafał Chatys, Hab. Ph.D.Sc. Eng.: Faculty of Mechatronics and Mechanical Engineering, Kielce University of Technology, al. 1000-lecia P.P. 7; 25-345, Kielce; PL, chatys@tu.kielce.pl

** Martinsh Kleinhofs, Prof. Hab. Ph.D.Sc. Eng.: Department of Aerial Vehicle Theory and Construction, Aeronautics Institute Riga Technical University, Lomonosova 1, Riga LV 1019, Latvia; LV, e-mail: martins.klenhofs@inbox.lv

*** Alexander Panich, M.Sc. Eng.: Department of Aerial Vehicle Theory and Construction, Aeronautics Institute Riga Technical University, Lomonosova 1, Riga LV 1019, Latvia; LV, e-mail: aleksandrs.panichs@gmail.com

$\dagger \quad$ Krzysztof Piernik, M.Sc. Eng.: Faculty of Mechatronics and Mechanical Engineering, Kielce University of Technology, al. 1000-lecia P.P. 7; 25-345, Kielce; PL, krzysztofpiernik@gmail.com
} 
Taking this into consideration (all available physical parameters of the layered composite), as a result of structural complexities, it is necessary to link them in real dependencies and mathematical model (i. e. fibers, fiber bundles of "elementary fiber bundle", unidirectional material or composite). The experiments confirmed, that mechanical properties (such as strength, modulus of elasticity, etc.), together with the complexity of the composite structure are lower. This means, that the average fiber strength $\left(\mathrm{S}_{\mathrm{f}}\right)$ is greater than the average thread strength $\left(\mathrm{S}_{\mathrm{H}}\right)$, and the average thread strength, is higher than the average strength of unidirectional material (UD) in the form of fabric, fibre mat, which we can be presented with the following assumption:

$$
\mathrm{S}_{\text {fiber }}>\mathrm{S}_{\text {fiber bundles }}>\mathrm{S}_{\text {elementary fiber bundle }}>\mathrm{S}_{\text {composite }}
$$

Statistical theories of endurance are developed in the works of Bolotin and Paramonov and others. The dependence on fiber strength in the bundle was first described by Daniels, who calculated the maximum load in the bundle consisting of $\mathrm{n}$ - fibers.

$$
Z=n \frac{1}{\omega}(1-Q(\omega))
$$

where: $\omega=1 / \mathrm{S}_{\mathrm{fi}} ; \mathrm{S}_{\mathrm{fi}}-$ limit of strength of «i » fiber; $\mathrm{Q}(\omega)$ - the degree of destruction of the bundle $(0 \ldots 1)$. In the model, verifying the strength properties of the composite, it was assumed, that the stress distribution in the volume is uniform, and the destruction of the fibers was based on a critical micro volume $\left(\mathrm{L}_{\mathrm{kr}}\right)$, which consists of a large number of components with individual physical and mechanical properties (Rozen dependence).

$$
L_{k r}=d_{f}\left[\left(\frac{1-v^{0,5}}{v^{0,5}}\right) \cdot \frac{E_{f}}{G_{m}}\right]^{0,5} \arccos h\left[\frac{1-(1-\varphi)^{2}}{2 \cdot(1-\varphi)}\right]
$$

where: $\mathrm{d}_{\mathrm{f}}-$ diameter of the fiber; $v$ - volume of the fiber; $E_{f}-$ Young's modulus of the fiber; $G_{m}-$ Kirchhoff modulus of the matrix; $\varphi$ - the coefficient of interaction between fiber and matrix $(\varphi=0,97 \%)$.

The location of reinforcement buckling (fibers) is difficult and accidental. The destruction process increases as a result of load increase between the fibers, during stress regrouping on neighboring fibers, determining maximum stresses in the destruction zone $\left(\sigma_{\max }\right.$ - its smallest value will determine the composite's strength):

$$
S=\frac{2 \tau_{l o k}}{\beta r}\left[\frac{1}{\tanh \left(\frac{\beta l}{2}\right)}-\frac{1}{\sinh \left(\frac{\beta l}{2}\right)}\right] .
$$

where: $\beta$ - const. $(\beta=1 / \mathrm{B}) ; r$ - radius of the fibre; $l$ - length of the fibre (critical length); $\tau_{l o k}-$ tangential stress.

\section{Methodology of statistical analysis for estimation the strength of a laminate with a polymer matrix}

We designed layered composite and an "elementary component bundle" by the vacuum bag method (Chatys, 2012), using epoxy-glass laminate $\left(\right.$ UDO $^{\circledR}$ fiberglass type ES and resin LH 160) and the structure $[0-45-0]_{S}$ was selected. The value of strength (S) and Young's modulus (E) after a static tensile test (Tab. 1) of the layered composite (containing laminate of 21 samples), were determined at 488.24 $\mathrm{MPa}$ and $21.93 \mathrm{GPa}$, respectively, which were characterized by a slight variation (caused by defects in laminate structure and technological aspects such as parameters of samples cutting). However, the average strength and E "elementary component bundle" of 25 samples was $30 \%$ and about $6 \%$ higher, respectively, than the laminate samples (at the level of 636.65 MPa and 20.75 GPa). Properties of fiber can be modeled until a certain extent, if we know statistical (parameters like mean $-\bar{S}$, Standard deviation - $\mathrm{S}_{\text {tdev }}$, dispersion $-\mathrm{S}_{2}$, or variation coefficient $-\mathrm{V}$ ) behavior of components (i.e. their transition from a simple structure into a complex - change of mechanical and physical properties from fiber to laminate, through unidirectional material). 
Tab. 1: Parameters of statistical treatment of $S$ and E laminate and "elemental component bundle" (for normal and logarithmic scale)

\begin{tabular}{|c|c|c|c|c|c|c|}
\hline \multirow{3}{*}{$\mathrm{S}$ of the laminate } & $\mathrm{n}$ & scale & Mean $\overline{\mathrm{S}}, \mathrm{MPa}$ & Standard deviation, $\mathrm{S}_{\mathrm{tdev}}$ & Dispersion, $\mathrm{S}^{2}$ & Variation, $\mathrm{V}$ \\
\hline & \multirow{2}{*}{21} & nor & 488.242 & 28.745 & 22.096 & 0.0453 \\
\hline & & $\log$ & 6.189 & 0.058 & 2.487 & 0.4019 \\
\hline \multirow{3}{*}{$\begin{array}{l}\text { S of the "elementary } \\
\text { component bundle " }\end{array}$} & $\mathrm{n}$ & scale & Mean, $\overline{\mathrm{S}} \mathrm{MPa}$ & Standard deviation, $\mathrm{S}_{\mathrm{tdev}}$ & Dispersion, $\mathrm{S}^{2}$ & Variation, $\mathrm{V}$ \\
\hline & \multirow{2}{*}{25} & nor & 636.656 & 28.745 & 28.745 & 0.0396 \\
\hline & & $\log$ & 6.4138 & 0.14987 & 0.058495 & 0.2749 \\
\hline \multirow{3}{*}{$\mathrm{E}$ of the laminate } & $\mathrm{n}$ & scale & Mean $\bar{E}, \mathrm{GPa}$ & Standard deviation, $\mathrm{S}_{\mathrm{tdev}}$ & Dispersion, $\mathrm{S}^{2}$ & Variation, $\mathrm{V}$ \\
\hline & \multirow{2}{*}{21} & nor & 21.925 & 477.835 & 4.682 & 0.2136 \\
\hline & & $\log$ & 3,085 & 3.1047 & 1.756 & 0.5693 \\
\hline \multirow{3}{*}{$\begin{array}{l}\text { E of the "elementary } \\
\text { component bundle" }\end{array}$} & $\mathrm{n}$ & scale & Mean $\overline{\mathrm{E}}, \mathrm{GPa}$ & Standard deviation, $\mathrm{S}_{\mathrm{tdev}}$ & Dispersion, $\mathrm{S}^{2}$ & Variation, $\mathrm{V}$ \\
\hline & \multirow{2}{*}{25} & nor & 20.747 & 510.096 & 4.554 & 0.2195 \\
\hline & & $\log$ & 3.0136 & 3.4714 & $1 ., 736$ & 0.5760 \\
\hline
\end{tabular}

Tab. 2: Checking the assumed hypothesis (Paramonov, 2012)

\begin{tabular}{cccc}
\hline Parameter & 0,99 & 0,95 & 0,9 \\
\hline$D^{*}=\left(D_{n}-\frac{0,2}{n}\right) \cdot\left(\sqrt{n}+0,26+\frac{0,5}{\sqrt{n}}\right)$ & 0,99 & 1,094 & 1,304 \\
\hline
\end{tabular}

The mechanical properties decrease as a result of the structural complexity of the material. Assuming that, the examined data sets of laminate samples and "elementary component bundle" of the epoxy matrix (i. e. data populations S and E) are subject to normal and logarithmic - normal distribution (Fig. 1; Fig. 2), the sets of these data populations were ordered from the smallest to the maximum size (in scale normal and logarithmic).

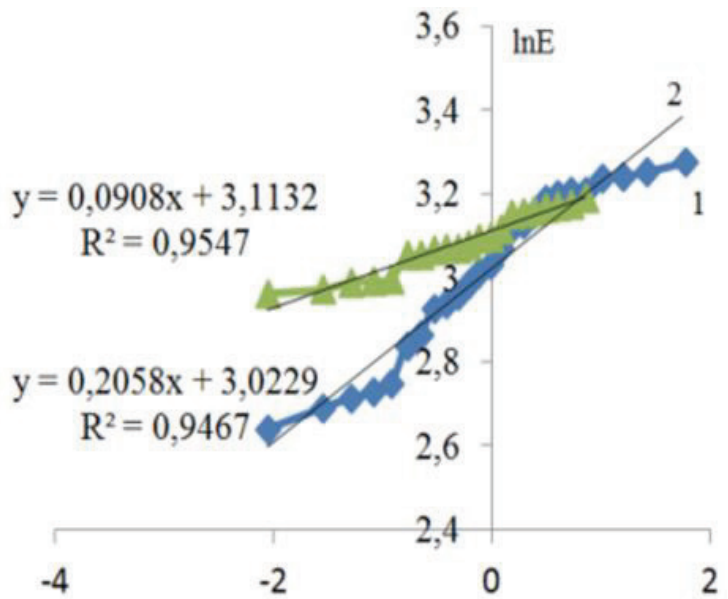

Fig. 1: The log-normal distribution of the $E$ of the laminate (1) data population and the "elementary component bundle" (2).

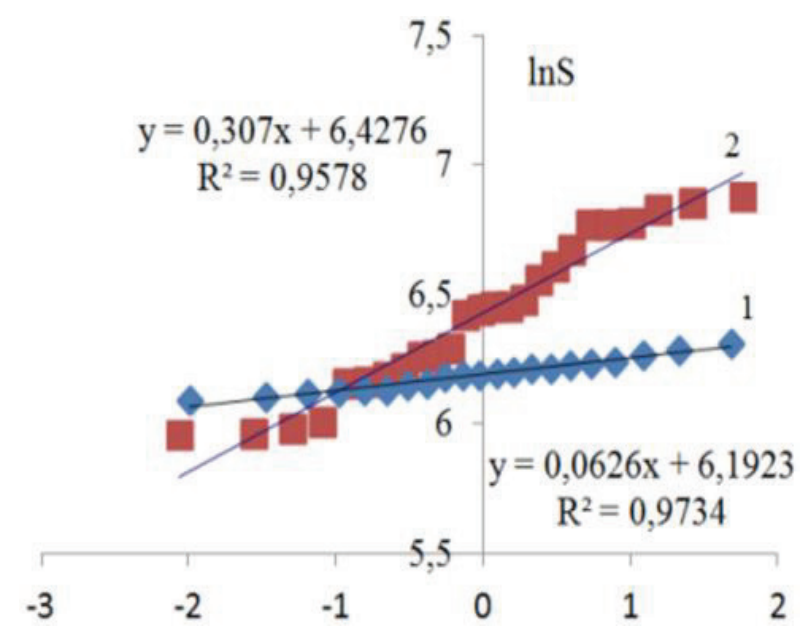

Fig. 2: The log-normal distribution of the strength of the laminate (1) data population and the "elementary component bundle" (2).

The confirmation of validity, in comparison with the admissible probability value (Tab. 2) of the adopted $\mathrm{S}$ distributions for laminate samples and "elementary component" samples was verified by the Kolmogorov criterion (see Table 2: D* of the elementary component bundle $=0.76081<0.99$ and $\mathrm{D}$ * laminate $=0.516768<0.99$ ) and graphical method (Fig. 3; Fig. 4), which we cannot say about the E- 
processing (the $\mathrm{D} *$ value for $\mathrm{E}$ "elementary component bundle" was $2.4734>1.304$, and for the $\mathrm{E}$ laminate, $2.3627>1.304$ was determined).

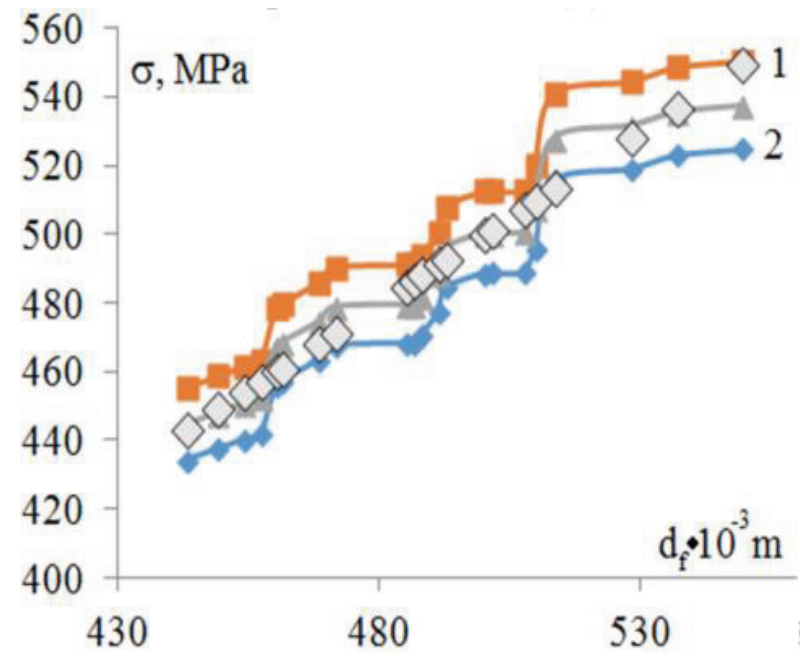

Fig. 3: The upper (1) and lower (2) confidence limits of the predicted $S$ from 21 laminate data population for the normal scale.

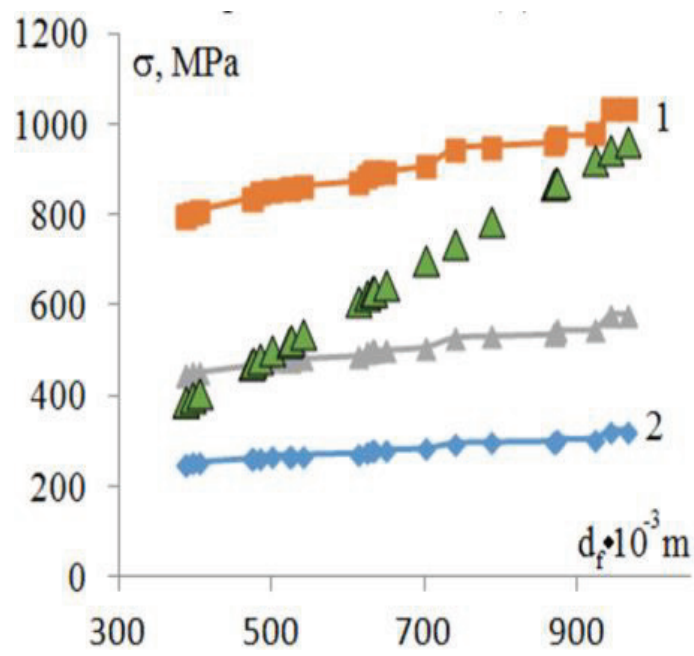

Fig. 4: The upper (1) and lower (2) confidence limits of the predicted $S$ from the 25 'elementary component bundle' data population for the normal scale.

\section{Conclusions}

The above assumption of the accuracy for selecting a given probability for the 21 and 25 sample populations for the "elemental component bundle" and for the laminate proved to be valid only in the case of strength (what we cannot say about E). Therefore, following the above statement, the value of $\mathrm{E}$ (average) is not an adequate value, allowing to properly estimate the strength of the laminate, as a result of not only the complexity of the structure, but also the influence of the technological parameters for the composite formation.

\section{References}

Blasiak, M. and Blasiak, S. (2017) The application of integral transforms to solving partial differential equations of the fractional order. In: Engineering Mechanics 2017, Brno University of Technology, Brno, pp. 150-153.

Chatys, R. (2012) Investigation of the Effect of Distribution of the Static Strength on the Fatigue Failure of a Layered Composite by Using the Markov Chains Theory, Mechanics of Comp. Materials, 48, 6, pp.629-639.

Chatys R., Skrobacki Z. (2010) Applying the Brown method to forecast the failure of laminate composite, Maintenance and Reliability No3 (47), 2010, pp. 56-66, ISBN: 1507-2711.

Paramonov, Ju. M. (1992) Methods of Mathematical Statistics in Problems on the Estimation and Maintenance of Fatigue Life of Aircraft Structures (in Russian), Riga, RIIGA.

Urbahs, A., Jonaite, I. (2013) Features of the use of unmanned aerial vehicles for agriculture applications, Aviation, 17 (4), pp. 170-175. 